\title{
MM5 v3.6.1 and WRF v3.5.1 model comparison of standard and surface energy variables in the development of the planetary boundary layer
}

\author{
C.-S. M. Wilmot, B. Rappenglück, X. Li, and G. Cuchiara \\ Department of Earth and Atmospheric Sciences, University of Houston, Houston, Texas, USA \\ Correspondence to: B. Rappenglück (brappenglueck@uh.edu) \\ Received: 19 March 2014 - Published in Geosci. Model Dev. Discuss.: 29 April 2014 \\ Revised: 21 September 2014 - Accepted: 25 September 2014 - Published: 18 November 2014
}

\begin{abstract}
Air quality forecasting requires atmospheric weather models to generate accurate meteorological conditions, one of which is the development of the planetary boundary layer (PBL). An important contributor to the development of the PBL is the land-air exchange captured in the energy budget as well as turbulence parameters. Standard and surface energy variables were modeled using the fifth-generation Penn State/National Center for Atmospheric Research mesoscale model (MM5), version 3.6.1, and the Weather Research and Forecasting (WRF) model, version 3.5.1, and compared to measurements for a southeastern Texas coastal region. The study period was 28 August1 September 2006. It also included a frontal passage.

The results of the study are ambiguous. Although WRF does not perform as well as MM5 in predicting PBL heights, it better simulates energy budget and most of the general variables. Both models overestimate incoming solar radiation, which implies a surplus of energy that could be redistributed in either the partitioning of the surface energy variables or in some other aspect of the meteorological modeling not examined here. The MM5 model consistently had much drier conditions than the WRF model, which could lead to more energy available to other parts of the meteorological system. On the clearest day of the study period, MM5 had increased latent heat flux, which could lead to higher evaporation rates and lower moisture in the model. However, this latent heat disparity between the two models is not visible during any other part of the study. The observed frontal passage affected the performance of most of the variables, including the radiation, flux, and turbulence variables, at times creating dramatic differences in the $r^{2}$ values.
\end{abstract}

\section{Introduction}

Due to a combination of complex chemical and meteorological interactions, Houston suffers from air pollution problems. Metropolitan traffic and a bustling refinery industry generate primary pollutants as well as precursors for secondary pollutants such as ozone. Despite the simple topography of the area, Houston's proximity to the Gulf of Mexico leads to a complex meteorological system that is influenced by both synoptic-scale and local land-sea breeze circulations. Various studies examining the interaction between these forcings have often noted that some of the most severe ozone exceedance days have occurred during stagnant periods when local and synoptic forces have clashed (Banta et al., 2005; Rappenglück et al., 2008; Langford et al., 2010; Tucker et al., 2010; Ngan and Byun, 2011).

In order to alert people to potentially health-threatening pollution levels, numerical weather prediction (NWP) models coupled to chemical models are used to predict the weather and its subsequent effect on atmospheric chemistry for the area. Two such models are the fifth-generation Penn State/National Center for Atmospheric Research mesoscale model (MM5; Grell et al., 1994) and the Weather Research and Forecasting (WRF) model (Skamarock et al., 2008). The MM5 model has been used extensively to simulate meteorological inputs for use in air quality models such as the Community Multiscale Air Quality (CMAQ; Byun and Schere, 2006) model.

Some studies, such as that done by Mao et al. (2006), have examined MM5 in the capacity of a coupled model, endeavoring to understand how changing the meteorological forcings affects the atmospheric chemistry output. Similarly, 
Ngan et al. (2012) looked at MM5 performance in connection with the CMAQ model ozone predictions. Other studies, such as was done by Zhong et al. (2007), have instead looked directly at MM5 output in order to better understand the meteorological parameterizations most appropriate for the local area.

Although MM5 is still being used for research purposes, the next-generation WRF model is now in general use. Developers of MM5 physics have imported or developed improved physics schemes for WRF, such as discussed in Gilliam and Pleim (2010), who found that the errors in all variables studied across the domain were higher in MM5 than in either WRF run with a similar configuration or the WRF run with a more common configuration. Their final conclusion was that the WRF model was now at a superior level to MM5 and should therefore be used more extensively, especially to drive air quality models. Hanna et al. (2010) tested the Nonhydrostatic Mesoscale Model core for WRF (WRFNMM) against MM5 for boundary layer meteorological variables across the Great Plains, and Steeneveld et al. (2010) used intercomparisons between MM5 and WRF to examine longwave radiation in the Netherlands. Both of these studies came to the conclusion that, in general, WRF outperformed MM5.

The common parameters examined in all of these previous studies are the planetary boundary layer (PBL) schemes and land surface models (LSMs), because in spite of improvements in predictions of standard atmospheric variables such as surface temperature and wind fields, characteristics of the PBL, especially PBL height, continue to elude modelers. For example, when Borge et al. (2008) did a comprehensive analysis of WRF physics configurations over the Iberian Peninsula, PBL height estimates for two observation sites were poor at night and during the winter, which are classically periods of stable boundary layer development. Other studies have found similar performance with PBL height (Wilczak et al., 2009; Hanna et al., 2010; Hu et al., 2010).

The land surface model is a key component of meteorology and air quality models. In meteorology modeling land surface exchange process are based on land cover categories within each modeling grid. It controls the partitioning of available energy at the surface between sensible and latent heat, and it controls the partitioning of available water between evaporation and runoff. In air quality modeling chemical surface fluxes are modeled based on different land cover categories. In this work the Noah land surface model (LSM) was used for both MM5 and WRF. The main objective of this scheme is to provide four parameters to the meteorological model: surface sensible heat flux, surface latent heat flux, upward longwave radiation, and upward shortwave radiation. LSMs are important because these variables represent the redistribution of energy at the surface atmosphere interface, and consequently impact other variables such as PBL evolution, temperature, etc. The Noah scheme requires three input parameters: vegetation type, soil texture, and slope. All other parameters used as input for this model can be specified as a function of the above three parameters. Different land surface data sets can present distinct results for the energy redistribution in the model, consequently impacting the dynamic characteristics of simulation.

Although many of these studies examine the sensitivity of WRF to PBL scheme and LSMs, not as much attention has been given to evaluating the effects of the energy balance variables generated by these various schemes. The complex interaction between latent and sensible heat, radiation and ground flux all affect the performance of meteorological variables, which in turn affect boundary layer properties such as PBL height. Analyzing the performance of these variables within a model should give further insight into the mechanisms that affect boundary layer properties, but these energy balance variables are not as commonly evaluated in the model because of a lack of observations.

Variations of the PBL height play an important role in air quality. Studies performed during the first and second Texas Air Quality Study (TexAQS-2000, TexAQS-II) have noted an increase in ozone after a frontal passage in the Houston area (Wilczak et al., 2009; Rappenglück et al., 2008; Tucker et al., 2010). This study is conducted to determine how well the MM5 and WRF models simulate PBL height, variables affecting its development, and standard atmospheric variables for a frontal passage during TexAQS-II.

\section{Observational data, models, and statistical analysis}

\subsection{Location}

The focus of this study is the University of Houston Coastal Center (UH-CC), which is located near the Gulf of Mexico coast $\left(29^{\circ} 23^{\prime} 16.67^{\prime \prime} \mathrm{N}, 95^{\circ} 02^{\prime} 29.09^{\prime \prime} \mathrm{W}\right)$ and is surrounded by approximately 200 acres $\left(0.81 \mathrm{~km}^{2}\right)$ of prairie grass (Fig. 1). This location was selected both because it is the location of previous field studies (Clements et al., 2007; Zhong et al., 2007) and is clear of surrounding structures that would interfere with the natural meteorological processes. Its micrometeorological setup is comprehensively described in Clements et al. (2007). Most of the measurements used in this study were taken from $10 \mathrm{~m}, 2 \mathrm{~m}$, or at the surface. Using a parameterized Lagrangian back-trajectory footprint model according to Kljun et al. (2004), it is possible to estimate maximum impact distances and $90 \%$ impact boundaries of the footprint affecting the observations (available at http://footprint.kljun.net/). Typical values for the daytime surface friction velocity $u^{*}$ are about $0.3-0.5 \mathrm{~m} \mathrm{~s}^{-1}$, for the standard deviation of the vertical velocity fluctuations about $0.7-0.9 \mathrm{~m} \mathrm{~s}^{-1}$. The roughness length is set to $0.07 \mathrm{~m}$ and is the same as used in the model simulations. For $10 \mathrm{~m}$ measurements this yielded maximum impact distances of 80 $98 \mathrm{~m}$ and $90 \%$ impact boundaries of $219-270 \mathrm{~m}$, which is well within the surrounding prairie grass area. Most of the 


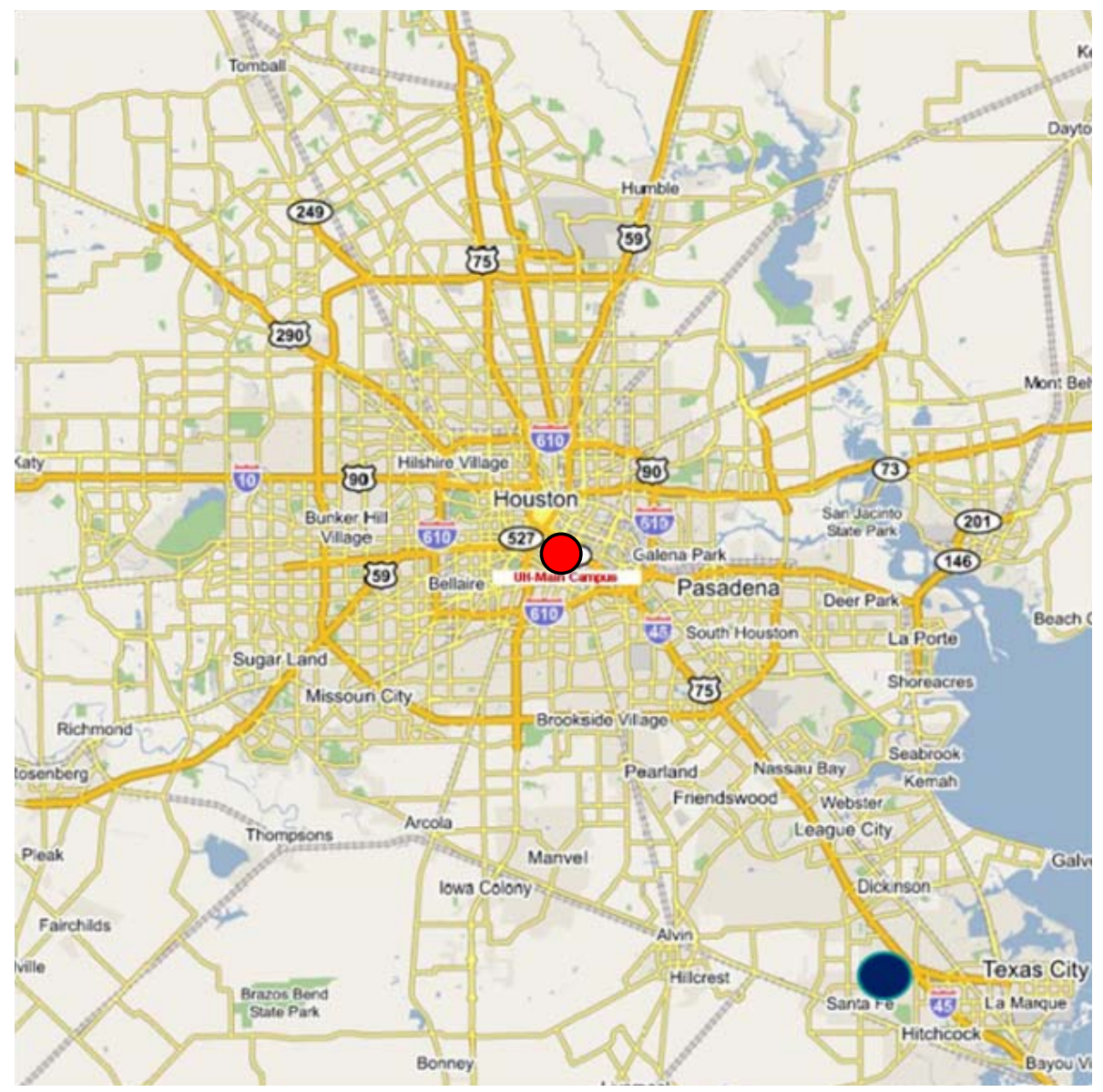

Figure 1. Location of model and measurements. The dark blue dot represents the UH Coastal Center and the red dot represents the UH main campus where the radiosondes were launched.

modeling and observation data were extracted from this location with the exception of the radiosondes, which were launched from the UH main campus (Rappenglück et al., 2008), and wind fields for the inner WRF domain, which were provided by the Texas Commission on Environmental Quality (TCEQ) Continuous Ambient Monitoring Stations (CAMS) in the surrounding area.

\subsection{Observational data}

\subsubsection{Measurement tower instrumentation}

During the study period 28-31 August 2006, both standard and energy budget surface variables were being measured (Table 1). Instrumentation included an R. M. Young 5103 anemometer to capture $10 \mathrm{~m}$ wind speeds (WDIR10) and directions (WSPD10), a Campbell Scientific, Inc. (CSI) CS-500 probe for $2 \mathrm{~m}$ temperature (TEMP2) and $2 \mathrm{~m}$ water vapor mixing ratio $(\mathrm{Q} 2)$, and a Kipp \& Zonen CNR1 four-component net radiometer to capture incoming shortwave (SWDOWN), incoming longwave (LWDOWN), outgoing shortwave (SWUP), and outgoing longwave radiation.
Table 1. Variable names and descriptions for the study.

\begin{tabular}{ll}
\hline Variable name (units) & Description \\
\hline TEMP2 $\left({ }^{\circ} \mathrm{C}\right)$ & Temperature at $2 \mathrm{~m}$ \\
Q2 $\left(\mathrm{g} \mathrm{kg}^{-1}\right)$ & Water vapor mixing ratio at $2 \mathrm{~m}$ \\
WSPD10 $\left(\mathrm{m} \mathrm{s}^{-1}\right)$ & Wind speed at $10 \mathrm{~m}$ \\
WDIR10 $\left({ }^{\circ}\right)$ & Wind direction at $10 \mathrm{~m}$ \\
LHFLUX $\left(\mathrm{Wm}^{-2}\right)$ & Latent heat flux at surface \\
SHFLUX $\left(\mathrm{Wm}^{-2}\right)$ & Sensible heat flux at surface \\
GRNDFLUX $\left(\mathrm{Wm}^{-2}\right)$ & Ground flux at surface \\
SWDOWN $\left(\mathrm{Wm}^{-2}\right)$ & Shortwave incoming radiation at surface \\
LWDOWN $\left(\mathrm{Wm}^{-2}\right)$ & Longwave incoming radiation at surface \\
SWUP $\left(\mathrm{Wm} \mathrm{m}^{-2}\right)$ & Shortwave outgoing radiation at surface \\
USTAR $\left(\mathrm{m} \mathrm{s}^{-1}\right)$ & Friction velocity \\
PBLH $(\mathrm{m})$ & Planetary boundary layer height \\
\hline
\end{tabular}

A three-dimensional (3-D) sonic anemometer (R. M. Young 8100) was used to determine sensible heat flux (SHFLUX) and in combination with a collocated LI-COR 7500 openpath infrared gas analyzer to collect data about latent heat flux (LHFLUX). Ground fluxes (GRNDFLUX) were 
measured using Radiation and Energy Balance System (REBS) soil heat flux plates.

Measurements were taken at a frequency of $1 \mathrm{~Hz}$ and averaged to $1 \mathrm{~min}$ (TEMP2, Q2, WSPD10, WDIR10) and 10 min (SWDOWN, LWDOWN, SWUP, SHFLUX, LHFLUX, GRNDFLUX). All measurements were then averaged to $1 \mathrm{~h}$ to compare to the hourly model data.

\subsubsection{Radiosonde data}

Radiosondes were not directly measured at the UH-CC during this study period, but were regularly launched from the UH main campus approximately $40 \mathrm{~km}$ away. RS-92 GPS sondes were used (Rappenglück et al., 2008). The difference in potential temperature vertical lines between the grid point representing the UH-CC and the UH was zero, which gave confidence that PBL heights measured at UH provide a reasonable approximation for model comparison at the UH-CC. Launches were performed at 06:00 CST and 18:00 CST for the first 2 days of the study period, and more were launched during the final 2 days of the study (Table 2). PBL heights were determined to be the height at which potential temperature begins to increase (Rappenglück et al., 2008). The first radiosonde launch was discarded for purposes of statistical analysis because it corresponded to the model initialization time step, which had a value of 0 .

\subsection{WRF model}

The WRF model used for the simulation was the Advanced Research WRF (WRF-ARW) model version 3.5.1 with the following physics configuration: WSM-3 class simple ice microphysics scheme (Hong et al., 2004), Dudhia shortwave radiation scheme (Dudhia, 1989), rapid radiative transfer model (RRTM) longwave radiation scheme (Mlawer et al., 1997), Yonsei University (YSU) (Hong et al., 2006) PBL scheme, and the MM5 land surface scheme (Noah LSM). The specific parameters of Noah LSM for the UC-CC site are listed in Table 3. The land surface data from the United States Geological Survey (USGS) were used. In past air quality studies in Houston we used YSU and found promising results (Czader et al., 2013), and recent intercomparisons with other PBL schemes for the same area showed that YSU simulates vertical meteorological profiles as satisfactorily as the Asymmetric Convective Model version 2 (ACM2); the Mellor-Yamada-Janjic (MYJ) and quasi-normal scale elimination (QNSE), but may be the best to replicate vertical mixing of ozone precursors (Cuchiara et al., 2014). The cumulus scheme is set to be identical to the MM5 one, which is described below.

The model was run on three nested domains using oneway nesting (Fig. 2). The horizontal grid scales were the $36 \mathrm{~km}$ CONUS domain, $12 \mathrm{~km}$ eastern Texas domain, and the $4 \mathrm{~km}$ Houston-Galveston-Brazoria domain. All simulation results are taken from the $4 \mathrm{~km}$ domain grid cell centered

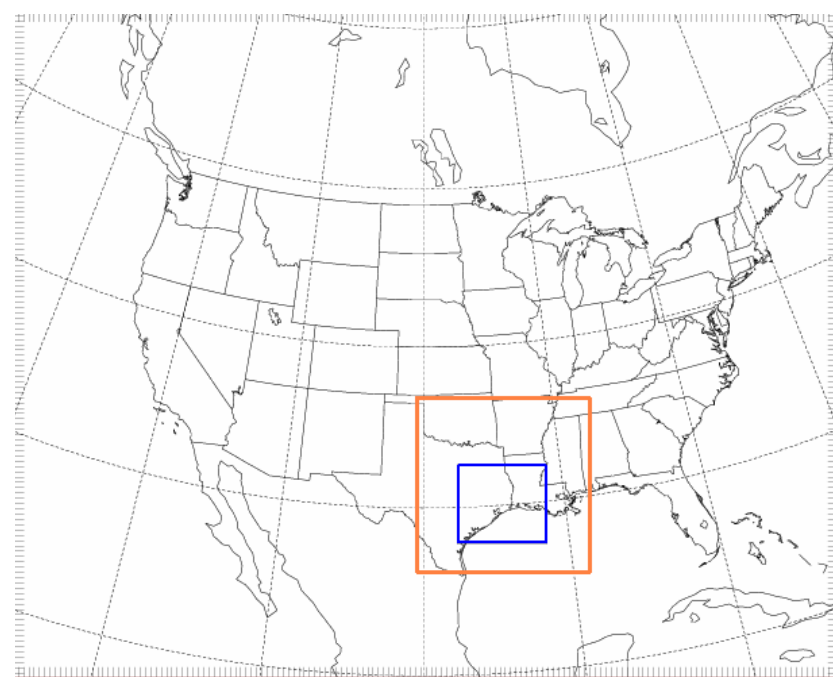

Figure 2. Nesting domain for WRF and MM5 model. The blue box is the $4 \mathrm{~km}$ domain that all model outputs were extracted from.

over the UH Coastal Center (Fig. 1) and is thus a point-togrid cell comparison. The $90 \%$ boundaries of the footprint of the observations fall within this grid cell. No observational nudging was used to avoid any potential effects introduced by nudging procedures. The model was initialized at 00:00 UTC on 28 August 2006 and ended at 23:00 UTC on 1 September 2006. The North America Mesoscale (NAM) model was used as meteorological input.

\subsection{MM5 model}

In order to examine any improvements made from the MM5 to WRF simulations, data extracted from an MM5 simulation were used for a baseline comparison for the Houston case (Table 4). Similarly to previous studies by Ngan et al. (2012) for TexAQS-II in Houston, we applied MM5, version 3.6.1. The physics options included the Medium-Range Forecast (MRF; Hong and Pan, 1996) PBL scheme, Noah LSM, simple ice microphysics scheme, and RRTM radiation scheme. The USGS land use data were used. No observational nudging was used. The same horizontal grid scale as for WRF was used. The cumulus parameterization is set to Grell-Devenyi ensemble scheme (Grell and Devenyi 2002) for $36 \mathrm{~km}$ domain, Kain-Fritsch scheme (Kain, 2004) for $12 \mathrm{~km}$ and none for $4 \mathrm{~km}$ domain. The choice of no cumulus in $4 \mathrm{~km}$ is to suppress the unwanted fake thunderstorms frequently popping up in the model. For MM5 the Eta Data Assimilation System (EDAS) was used.

\subsection{Differences between the WRF and MM5 configurations}

The differences between the two models' configurations are the cloud scheme and the land analysis used for the initialization. Cloudiness has a large impact on SWDOWN and 
Table 2. Radiosonde launch times (CST).

\begin{tabular}{cccccc}
\hline 27 Aug 2006 & 28 Aug 2006 & 29 Aug 2006 & 30 Aug 2006 & 31 Aug 2006 & 1 Sep 2006 \\
\hline $18: 00$ & $06: 00$ & $06: 00$ & $06: 00$ & $04: 00$ & $04: 00$ \\
& $18: 00$ & $18: 00$ & $12: 00$ & $06: 00$ & $06: 00$ \\
& & & $18: 00$ & $09: 00$ & $09: 00$ \\
& & & $12: 00$ & $12: 00$ \\
& & & $15: 00$ & $15: 00$ \\
& & & & $18: 00$ & \\
& & & & $21: 00$ & \\
\hline
\end{tabular}

Total no. of radiosondes: 20

Table 3. Noah LSM parameters used for the UH-CC site in the MM5 and WRF simulations.

\begin{tabular}{llll}
\hline Parameter & Meaning & Value & Category \\
\hline LU_INDEX IVGTYP & Land use index vegetation type & 2 & Dryland cropland and pasture \\
ISLTYPE & Soil type & 12 & Clay \\
VEGFRAC & Vegetation fraction & 55.20 & \\
SHDFAC & Green vegetation fraction & 0.80 & \\
LAI & Leaf area index & 4.96 & \\
EMISS & Emissivity & 0.97 & \\
ALBEDO & Albedo & 0.18 & \\
Z0 & Roughness length & 0.07 & \\
\hline
\end{tabular}

Table 4. Model simulation configurations.

\begin{tabular}{lcccc}
\hline Simulation & Model & PBL scheme & LSM & Land analysis \\
\hline MM5 & MM5 & MRF & Noah & EDAS \\
WRF & WRF-ARW & YSU & Noah & NAM \\
\hline
\end{tabular}

related subsequent processes. Cloudiness represented by corresponding schemes in WRF and MM5 is likely associated with some higher degree of uncertainty. For instance, cloud fraction in a grid box is assumed either 0 or 1 (Dudhia, 1989), which is certainly not precise enough. Unfortunately, in our study we did not have quantitative information about observed cloudiness, and thus we were not able to perform validation studies for these schemes. The EDAS and NAM land surface data sets are similar and use similar observational techniques for data interpolation, but the EDAS runs every $3 \mathrm{~h}$, which allows for higher-resolution temporal interpolation than the NAM data, which only runs every $6 \mathrm{~h}$ (EDAS Archive Information, National Weather Service Environmental Center). Using a more high-resolution data set should lead to better first-guess and ongoing simulations in MM5.

The YSU and MRF PBL schemes use nonlocal closure and rely heavily on the Richardson number (Ri) to compute PBL height for different regimes (e.g., stable, unstable, and neutral PBLs). Both of these PBL schemes essentially define PBL height as the height at which a critical $\mathrm{Ri}$ is reached: 0.5 for the MRF scheme and 0.0 for the YSU scheme (Skamarock et al. 2008). For unstable conditions the PBL height in the YSU scheme is determined to be the first neutral level based on the bulk Richardson number calculated between the lowest model level and the levels above (Hong et al. 2006).

\subsection{Statistical analysis}

\subsubsection{Calculated statistics}

For the purposes of this study, the coefficient of determination $\left(r^{2}\right)$, the root mean square error (RMSE) and bias are displayed. The RMSE describes the magnitude of the difference between predicted and observed values. The $r^{2}$ indicates the proportionate amount of variation in the response variable $y$ explained by the independent variables $x$ in the linear regression model. The larger the $r^{2}$, the more variability is explained by the linear regression model. The $r^{2}$ was calculated using a linear model in Matlab. The bias and RMSE was determined as follows:

$\mathrm{BIAS}=\frac{1}{n} \sum\left(Y^{\prime}-Y\right)$,

$\operatorname{RMSE}=\sqrt{\frac{1}{n-1} \sum\left(Y^{\prime}-Y\right)^{2}}$,

where $n$ is the number of values, $Y^{\prime}$ is the modeled value, and $Y$ is the observed value. 
Table 5. Data clusters.

\begin{tabular}{lc}
\hline Cluster & Number of data points \\
\hline All & 114 \\
Daytime & 64 \\
Nighttime & 50 \\
Prefrontal & 44 \\
Postfrontal & 77 \\
\hline
\end{tabular}

\subsubsection{Determination of additional statistic groups}

Hourly values were collected from 00:00 CST on 28 August to 17:00 CST on 1 September, resulting in 114 data points (Table 5). Biases and $r^{2}$ values were evaluated for the complete data set as well as for diurnal and frontal clusters. For the diurnal statistics, daytime referred to any data between 06:00 CST and 18:00 CST. Rappenglück et al. (2008) discussed the frontal passage that occurred during this period, which occurred during the evening of 29 August. An examination of the meteorology shows that generally southerly winds gave way to sustained northerly winds on $29 \mathrm{Au}-$ gust around 18:30 CST, indicating this frontal passage. For the purposes of this study, the prefrontal period runs from 00:00 CST on 28 August to 19:00 CST on 29 August, and the postfrontal period runs from 20:00 CST on 29 August to 17:00 CST on 1 September.

\section{Results and discussion}

\subsection{Standard meteorological variables}

\subsubsection{Temperature}

WRF has the highest $r^{2}$ for all of the study period as well as when the data are separated into daytime, nighttime, prefrontal, and postfrontal time periods (Table 6). The largest differences between the WRF and MM5 model in the $r^{2}$ value occur at night and during prefrontal conditions, both of which have differences of 0.53 . However, the nighttime $r^{2}$ value for MM5 was the smallest at 0.04 , which reflects the variability in the nighttime temperature modeling. The WRF model has a higher nighttime $r^{2}$ value of 0.57 , but this value also represents the smallest $r^{2}$ value for the model, which implies that both models have difficulty getting nighttime temperatures correct. Batching the data into prefrontal and postfrontal groups had little effect on the $r^{2}$ values for WRF, but led to increased values in both of the MM5 models.

WRF and MM5 have about the same magnitude bias for the entire study period, but WRF has larger biases for the daytime and nighttime, while WRF has lower biases for prefrontal period, and in particular for the postfrontal period. The overall biases for all of the simulations are relatively low, but both WRF and MM5 underestimate temperatures by about half a degree during the day and overestimate temperatures by about one and a half degree at night for the entire study period (Table 6). These biases could possibly be attributed to too much moisture in the models, which would suppress temperature amplitudes. This warm nighttime bias is especially evident on the nights of 30 and $31 \mathrm{Au}-$ gust (Fig. 3). These biases could be the product of too much moisture in the model, which would lead to less suppressed temperature peaks. Another possibility is that there is too much nighttime surface energy in the model, which could lead to increased nighttime temperatures. Also, higher modeled nighttime winds could lead to a well-mixed nighttime atmosphere, which would prevent temperatures from dropping as low as they should in the model.

Steeneveld et al. (2010) noted that both of the models have difficulty simulating nighttime temperatures. That same study also mentioned that the MM5 warming and cooling trends tended to lag behind the observations, which is visible in the time series for the first half of this study as well (Fig. 3). The WRF model simulation does not have this same time lag.

\subsubsection{Water vapor}

WRF $r^{2}$ values for water vapor are lower than the MM5 $r^{2}$ values (Table 6). The overall $r^{2}$ values were highest for MM5, while the daytime $r^{2}$ values were highest for both WRF and MM5. MM5 had the highest overall and postfrontal values. Both of the models saw low $r^{2}$ values prior to the frontal passage, which only increased for MM5 following the frontal passage. WRF had the lowest postfrontal and prefrontal values. The water vapor mixing ratio $r^{2}$ values are relatively high for MM5 although they are lower than the temperature $r^{2}$ values. For WRF these values are consistently lower than the temperature $r^{2}$ values. Daytime water vapor mixing ratio tended to be higher than the overall $r^{2}$, while nighttime water vapor $r^{2}$ values were slightly lower than the overall $r^{2}$ for MM5, but significantly lower for WRF. MM5 overall, daytime, and nighttime $r^{2}$ values were higher than WRF. This is even more evident for the prefrontal and postfrontal conditions.

Table 6 shows that both models underestimated moisture for the entire study period with dry biases of $1.44 \mathrm{~g} \mathrm{~kg}^{-1}$ and $2.61 \mathrm{~g} \mathrm{~kg}^{-1}$ for WRF and MM5, respectively. During the day, this dry bias increases for both WRF and MM5 to $1.47 \mathrm{~g} \mathrm{~kg}^{-1}$ and $2.81 \mathrm{~g} \mathrm{~kg}^{-1}$. However, at night, the dry bias decreases to $1.40 \mathrm{~g} \mathrm{~kg}^{-1}$ and $2.36 \mathrm{~g} \mathrm{~kg}^{-1}$ for WRF and MM5, respectively. Zhong et al. (2007) modeled water vapor at the UH-CC and saw biases of 1.38 during the day, -0.63 at night, and 0.37 for the overall value, which indicated overestimation of moisture during the day and underestimation at night. The difference in the two models' moisture bias could be attributed to the different land initialization schemes used for the two models, but in either case temperature performance during the entire study period appears 
Table 6. Results for $r^{2}$ and bias for all, diurnal, and frontal conditions for temperature (TEMP2), water vapor mixing ratio (Q2), wind speed (WSPD10), wind direction (WDIR), incoming longwave radiation (LWDOWN), outgoing shortwave radiation (SWUP), and incoming shortwave radiation (SWDOWN).

\begin{tabular}{|c|c|c|c|c|c|c|c|c|c|c|c|c|c|c|}
\hline & \multicolumn{2}{|c|}{ TEMP2 } & \multicolumn{2}{|c|}{$\mathrm{Q} 2$} & \multicolumn{2}{|c|}{ WSPD10 } & \multicolumn{2}{|c|}{ WDIR10 } & \multicolumn{2}{|c|}{ LWDOWN } & \multicolumn{2}{|c|}{ SWUP } & \multicolumn{2}{|c|}{ SWDOWN } \\
\hline & WRF & MM5 & WRF & MM5 & WRF & MM5 & WRF & MM5 & WRF & MM5 & WRF & MM5 & WRF & MM5 \\
\hline$r^{2}$ & 0.78 & 0.56 & 0.37 & 0.73 & 0.28 & 0.40 & 0.02 & 0.29 & 0.52 & 0.64 & - & - & - & - \\
\hline$r^{2}$ _Day & 0.71 & 0.48 & 0.64 & 0.78 & 0.17 & 0.31 & 0.00 & 0.50 & 0.66 & 0.61 & 0.71 & 0.23 & 0.75 & 0.64 \\
\hline$r^{2} \_$Night & 0.57 & 0.04 & 0.10 & 0.66 & 0.09 & 0.45 & 0.09 & 0.03 & 0.31 & 0.47 & - & - & - & - \\
\hline$r^{2}$ _Prefront & 0.79 & 0.36 & 0.00 & 0.31 & 0.16 & 0.33 & 0.04 & 0.30 & 0.59 & 0.45 & 0.86 & 0.65 & 0.86 & 0.64 \\
\hline$r^{2}$ Postfront & 0.79 & 0.65 & 0.00 & 0.56 & 0.44 & 0.45 & 0.06 & 0.27 & 0.15 & 0.48 & 0.88 & 0.76 & 0.91 & 0.92 \\
\hline Bias & 0.24 & 0.23 & -1.44 & -2.61 & 1.70 & 0.18 & -21.48 & -2.41 & 0.34 & 3.00 & - & - & - & - \\
\hline Bias_Day & -0.71 & -0.62 & -1.47 & -2.81 & 1.69 & -0.11 & -37.89 & -8.32 & -5.46 & 2.76 & 15.93 & 60.49 & 77.85 & 17.04 \\
\hline Bias_Night & 1.46 & 1.33 & -1.40 & -2.36 & 1.72 & 0.54 & -0.47 & 5.17 & 7.78 & 3.30 & - & - & - & - \\
\hline Bias_Prefront & 0.59 & -0.73 & -1.32 & -2.77 & 1.35 & -0.08 & -35.82 & -10.23 & 6.16 & 4.35 & 11.27 & 79.12 & 61.38 & -24.00 \\
\hline Bias_Postfront & 0.02 & 0.84 & -1.51 & -2.51 & 1.93 & 0.34 & -12.47 & 2.51 & -3.31 & 2.15 & 6.29 & 4.38 & 32.58 & 30.65 \\
\hline RMSE & 1.95 & 2.71 & 2.76 & 3.00 & 2.08 & 0.97 & 145.97 & 94.58 & 15.36 & 14.41 & - & - & - & - \\
\hline RMSE_Day & 1.76 & 2.41 & 2.35 & 3.17 & 2.09 & 0.99 & 164.63 & 83.61 & 14.40 & 15.37 & 36.44 & 122.92 & 180.32 & 205.03 \\
\hline RMSE_Night & 2.18 & 3.06 & 3.21 & 2.78 & 2.07 & 0.94 & 117.85 & 107.00 & 16.52 & 13.08 & - & - & - & - \\
\hline RMSE_Prefront & 1.58 & 2.75 & 2.28 & 3.10 & 1.97 & 1.08 & 130.75 & 59.73 & 14.26 & 15.86 & 29.38 & 141.81 & 154.04 & 199.07 \\
\hline RMSE_Postfront & 2.16 & 2.69 & 3.03 & 2.94 & 2.15 & 0.89 & 154.77 & 111.02 & 16.02 & 13.41 & 25.96 & 34.28 & 121.71 & 116.30 \\
\hline
\end{tabular}

to be affected by more than the water vapor mixing ratios. For the 2 days following the frontal passage, the models' temperature and water vapor mixing ratio biases appear to be more coupled. WRF underestimates daytime temperature with a bias of $-3.31{ }^{\circ} \mathrm{C}$ and could correspond to a moist bias of $-3.05 \mathrm{~g} \mathrm{~kg}^{-1}$, while MM5 slightly overestimates daytime temperature with a bias of $0.12^{\circ} \mathrm{C}$ and could correspond to a moist bias of $-2.65 \mathrm{~g} \mathrm{~kg}^{-1}$. The days following the frontal passage were mostly cloudless, so temperature may be more directly affected by moisture. The fact that following the frontal passage the conditions are more dry could also be a contributing factor, as the observed water vapor mixing ratio dropped by approximately $4 \mathrm{~g} \mathrm{~kg}^{-1}$ for the remainder of the study period (figure not shown). Moisture bias effects could be magnified in light of much smaller moisture values.

For the 2 nights following the frontal passage, both models' dry biases are relatively close to the mean nighttime biases of the entire study period, but temperature biases are not proportional to these changes. The nighttime biases decrease by $0.84 \mathrm{~g} \mathrm{~kg}^{-1}$ and $0.09 \mathrm{~g} \mathrm{~kg}^{-1}$ for WRF and MM5, respectively, but both models clearly overestimate temperature on the nights of 30 and 31 August (Fig. 3). For the entire study period, the models have too warm nighttime biases of $1.46^{\circ} \mathrm{C}$ and $1.33^{\circ} \mathrm{C}$ for WRF and MM5, respectively; these warm biases increase to $2.22{ }^{\circ} \mathrm{C}$ and $2.61{ }^{\circ} \mathrm{C}$ for those 2 nights.

\subsubsection{Wind speed}

Wind speeds had generally low $r^{2}$ values, with the highest overall $r^{2}$ being the MM5 simulation using EDAS (Fig. 3). Separating data into day- and nighttime values did not increase the $r^{2}$ values; in fact, both day- and nighttime $r^{2}$ were lower than the overall values for both of the models. While the MM5 model bias was relatively small and slightly underestimated during the daytime, the WRF model overesti- mated with a much higher magnitude. Both models have the largest biases at night when wind speeds are overestimated, and with the highest overestimation occurring by the WRF model. Ngan et al. (2012) mention that modeled MM5 winds persisted for hours after the observed winds had died down at sunset. A similar trend is visible for a few nights of this study period in MM5, but is most clearly evident in the WRF model.

Wind speed $r^{2}$ values were equally low for both prefrontal and postfrontal conditions. However, clustering data by frontal condition led to having at least one higher $r^{2}$ value for each model than for all of the data combined (Table 6). In WRF, the prefrontal value was lower than the postfrontal value, and this was the lowest prefrontal value among the models. The MM5 model postfrontal value was higher. Prefrontal biases are low for MM5, but appreciably high for WRF. For both models biases increase in the postfrontal environment. Tucker et al. (2010) found that daytime winds tended to be higher and be more southerly following strong low level jet (SLLJ) nights, and they were weaker and either northerly or stagnant following weak LLJ (WLLJ) nights. Although it slightly overestimates wind speeds, WRF is able to better capture the post-SLLJ conditions on 28 August which correspond to prefrontal conditions. However, WRF persists in generating high winds on the days following two WLLJ nights (31 August and 1 September), which correspond to postfrontal conditions and lead to a much higher bias. The MM5 model does not suffer from high bias to the same extent, but it also tends to overestimate more following the postfrontal conditions corresponding to the post-WLLJ scenario. 


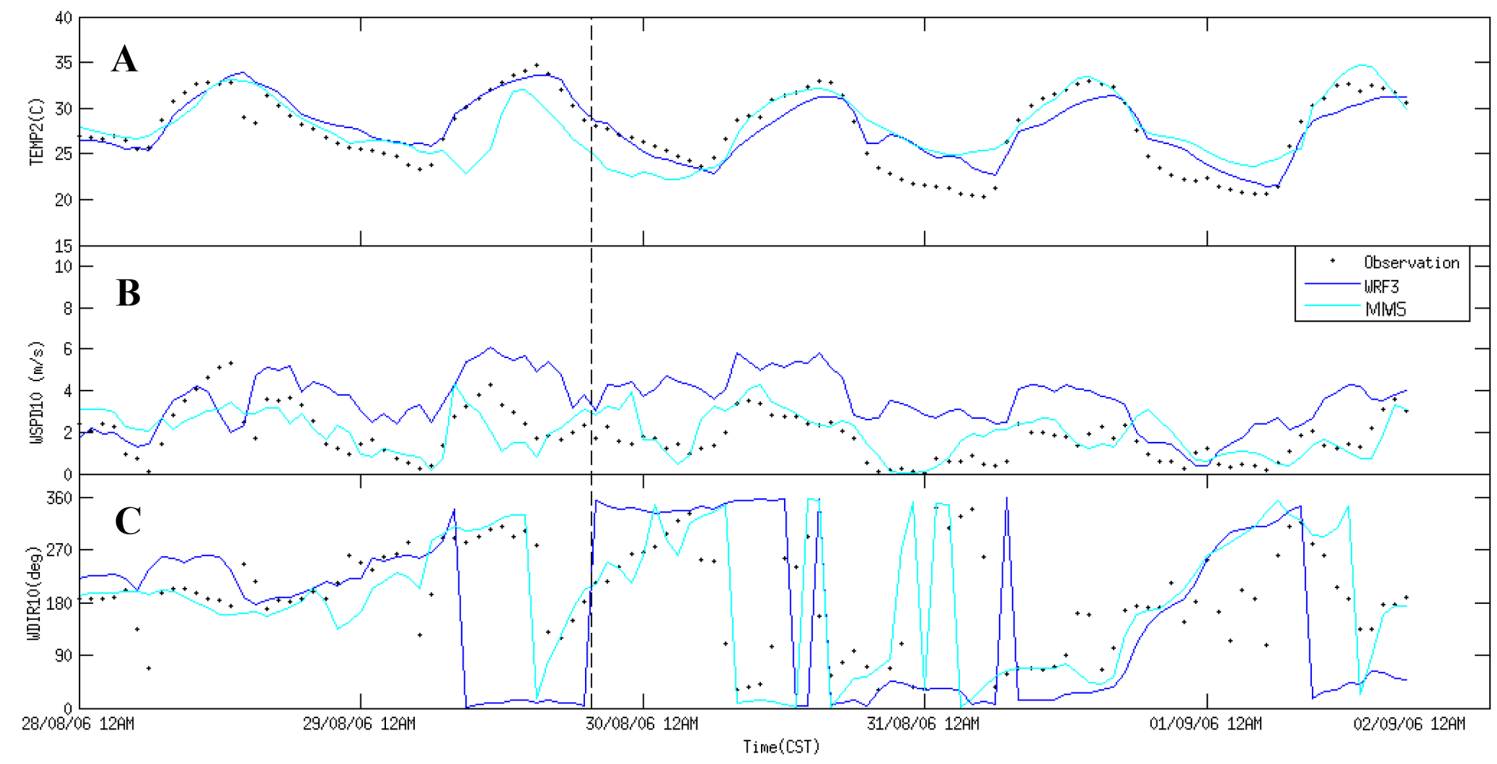

Figure 3. Time series of temperature (a), wind speed ((b), and wind direction (c) for observations (dots) and for the WRF (blue) and MM5 with EDAS (green) models. The dotted line marks the beginning of postfrontal conditions.

\subsubsection{Wind direction}

Wind direction $r^{2}$ values were generally low for the entire study period and at nighttime for both models, and only reach approximately 0.50 during the daytime (Table 6). Houston's proximity to the Gulf of Mexico generally means that there is a strong diurnal cycle as the temperature difference between the land and the water creates surface pressure gradients. This cycle tends to manifest itself in strong southerly winds during the daytime and more northerly winds in the evening and at night. However, during this time period the frontal passage led to more persistent northerly winds, which might have interfered with the normal cycle of the models (Fig. 3). The prefrontal and postfrontal $r^{2}$ values are both with values at or near 0.30 for MM5 and below 0.10 for WRF. During the study period, wind direction was variable as the front and the daytime wind cycle came into contact.

The magnitudes for the overall, daytime, and nighttime biases were an order of magnitude larger for WRF than for MM5 in most cases. Wind direction for the entire study was underestimated by $21.48^{\circ}$ and $2.41^{\circ}$ in WRF and MM5, respectively, which means that the wind directions were in the same quadrant, but for WRF started having more of an orthogonal wind component. During the daytime these bias magnitudes increase for both models. This could possibly be related to the frontal passage, especially during the day when the frontal passage and the land-sea breeze cycle led to stagnant air conditions and wind directions were variable. Southerly winds are associated with moist, ocean air, while north and northwesterly winds are associated with drier, continental air, so the direction of the wind in the models could relate to the level of water vapor mixing ratio found in the models.

\subsection{Energy budget variables}

\subsubsection{Radiation}

Longwave outgoing radiation is only available at the top of the atmosphere, not at the surface, for both WRF and MM5. As we restricted our analysis to the available model outputs at the surface only, this variable was removed from the study analysis, and only the other three components of radiation were studied (Table 6).

\section{Incoming longwave radiation}

The $r^{2}$ values for longwave radiation are often lower than for either temperature or water vapor mixing ratio, but are still relatively high (Table 6). WRF has a higher $r^{2}$ during the daytime than overall, while MM5 is slightly lower than the overall value during the daytime. The overall and daytime WRF $r^{2}$ values are about the same as the MM5 values, but at night MM5 has a slightly higher $r^{2}$ than the WRF model. Both models have relatively low nighttime $r^{2}$ values compared to either daytime or overall values.

Both models overestimate incoming longwave radiation with the largest overestimations occurring at night. WRF has larger biases than MM5 for daytime and nighttime. However, the minimum longwave radiation value recorded during this time period was $\sim 371 \mathrm{Wm}^{-2}$. Even the largest bias $\left(8 \mathrm{Wm}^{-2}\right)$ only represents a $2 \%$ overestimation of incoming longwave radiation. 


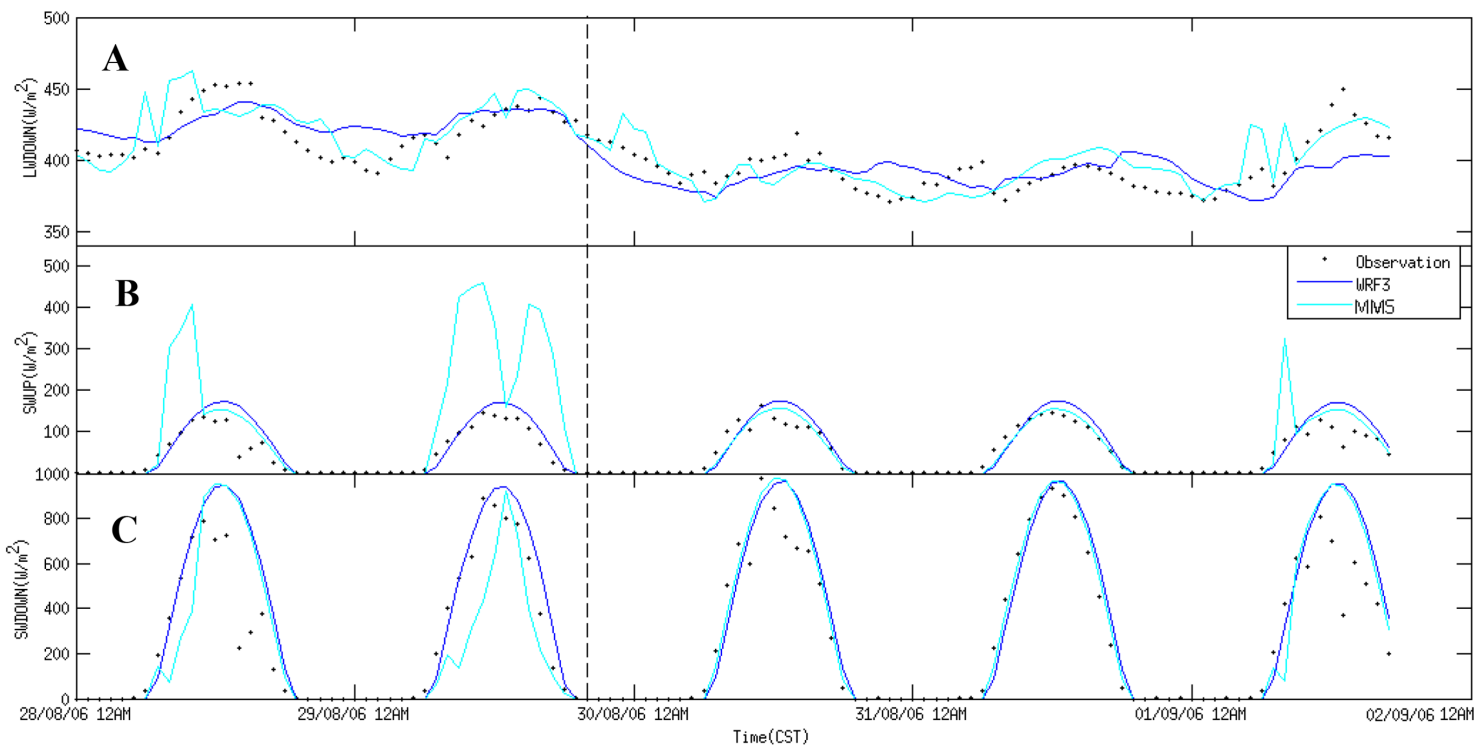

Figure 4. Time series for incoming longwave (a), outgoing shortwave (b), and incoming shortwave (c) radiation for observations (dots) and for the WRF (blue) and MM5 with EDAS (green) models.

There is a slight time lag in both the cooling and the warming trends for the longwave radiation for both models, but they both also attempt to capture the drop in radiation following the frontal passage (Fig. 4). Both of the models overestimated; prefrontal conditions produced the largest bias. In MM5 there is an almost 50\% drop in bias from the prefrontal to postfrontal data cluster, and a WRF even changed to underestimation. WRF had the lowest overall, but highest frontal cluster biases.

\section{Incoming/outgoing shortwave radiation}

The models treat outgoing radiation as a direct decrease caused by albedo. Therefore, both incoming and outgoing shortwave radiation are driven to 0 after sunset, leading to the "-" found in the tables for nighttime values. For outgoing radiation, the WRF model performs better than the MM5 model, which has very small $r^{2}$ values during the daytime (Table 6). These small $r^{2}$ values are most likely the result of the overestimations found during the early part of the study period when MM5 overestimates outgoing shortwave radiation by as much $337 \mathrm{Wm}^{-2}$ (Fig. 4) and results in daytime biases of $60 \mathrm{Wm}^{-2}$. This is a puzzling feature as it is not a consistent behavior. It predominantly occurs on the 2 prefrontal days. Also, the occurrence of these large deviations of SWUP in MM5 is accompanied by concurrent underprediction of SWDOWN in MM5; often these underpredictions in SWDOWN are of the similar magnitude as the overpredictions in SWUP, which points to a deficient energy distribution in MM5 on these days. Regardless of the nature of this deficiency, its impact is visible in corresponding underpredictions in the fluxes of sensible and latent heat (Fig. 5), and to some extent it is also reflected in the temperature time series (Fig. 3). The significant PBL underprediction in MM5 on 29 August (see discussion on PBL in Sect. 3.3) is likely due to the underprediction of sensible and latent heat in MM5 on that day (Fig. 5), which in turn might be associated with the deficient simulation of incoming and outgoing shortwave radiation by MM5 on the same day. While the overall flux in the WRF model is slightly overestimated, it is overestimated in MM5 with a magnitude of $33 \mathrm{Wm}^{-2}$.

For the first 2 days of the study period, incoming solar radiation (SWDOWN) did not reach maximum insolation peaks, possibly due to scattered cloud cover. Following the frontal passage on 29 August, cloud cover began to dissipate as observed incoming solar radiation began to increase, reaching maximum insolation on the afternoon of $31 \mathrm{Au}-$ gust before again devolving on 1 September. However, both models moved too soon in developing maximum insolation (Fig. 4).

During the daytime for the entire study period, both models tended to overestimate SWDOWN (Table 6). However, for the 2 clearest days of the study period, both WRF and MM5 overestimated incoming solar radiation by $75.5 \mathrm{Wm}^{-2}$ and $52.9 \mathrm{Wm}^{-2}$, respectively. While these values drop to $16.25 \mathrm{Wm}^{-2}$ and $17.27 \mathrm{Wm}^{-2}$ on the clearest day of the study, both models continue to overestimate incoming solar radiation. This excess energy in the models could appear as overestimations in the energy flux partitions for sensible, latent, and ground flux.

Incoming radiation $r^{2}$ values are generally higher than the outgoing values for both of the models (Table 6). WRF performs better than the MM5 model for all values. Both models tend to overestimate the radiation, but the magnitudes of the 


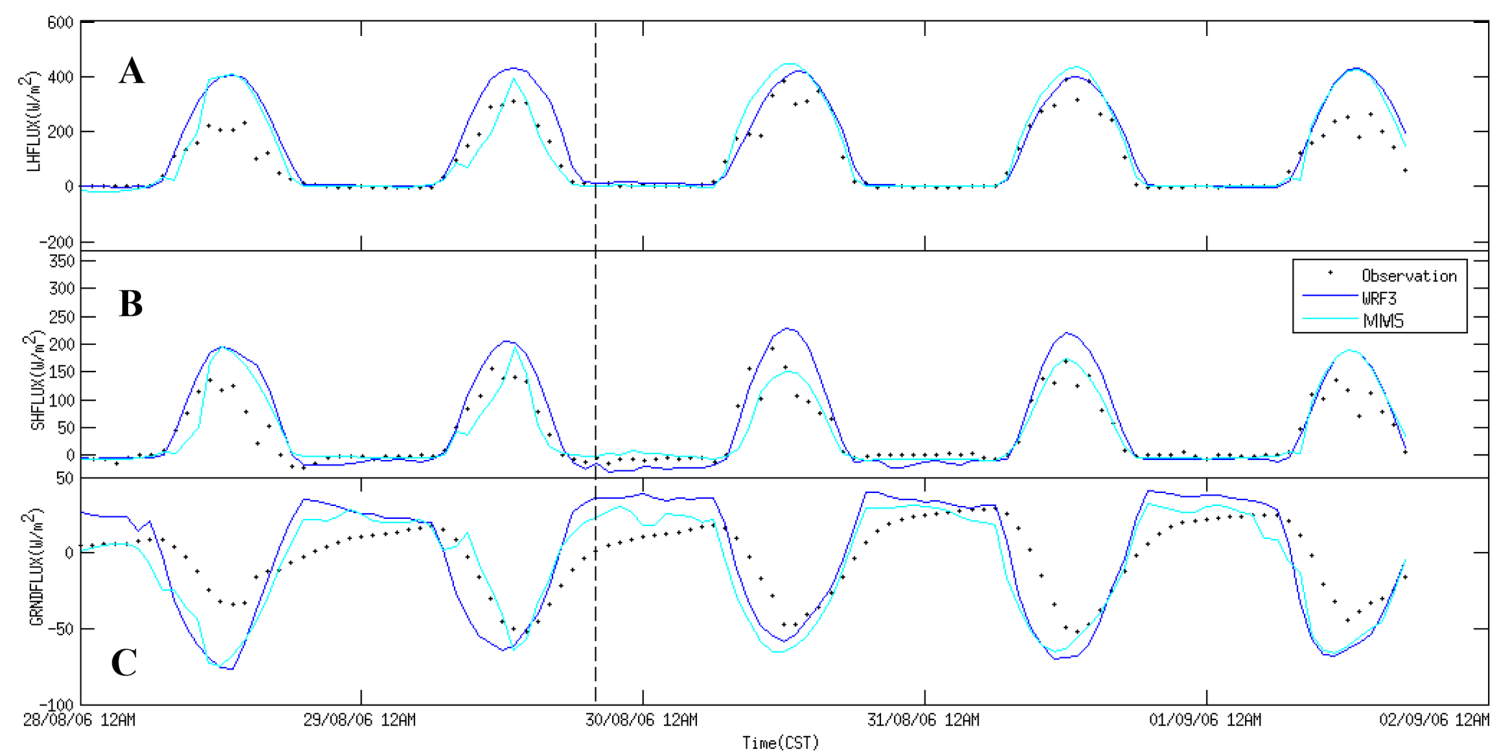

Figure 5. Time series for latent heat (a), sensible (b), and ground (c) flux for observations (dots) and for the WRF (blue) and MM5 with EDAS (green) models.

biases for incoming radiation are smaller for MM5, while the magnitudes of the biases for outgoing radiation are smaller for WRF (Table 6).

For both outgoing and incoming radiation, daytime $r^{2}$ values and biases could be affected by the delayed onset of daytime radiation in the models. Both models take an additional hour before seeing increased incoming and outgoing solar radiation values, which is especially visible following the frontal passage (Fig. 4). The averaging of the hourly observations when sunrise occurred in the middle of an hour may also contribute to the discrepancy between the observations and simulations. Incoming solar radiation has much smaller biases. The maximum daytime values reached $979 \mathrm{Wm}^{-2}$, leading to a maximum daytime average bias of only $1 \%$.

Similar to the outgoing shortwave radiation, both model runs for incoming shortwave radiation have larger postfrontal $r^{2}$ values (Table 6). Both of the models have comparable postfrontal $r^{2}$ values, but WRF has higher prefrontal $r^{2}$ values. While WRF overestimated, MM5 underestimated prior to the front, but both models overestimated similarly following the front. WRF had the largest bias in the prefrontal cluster.

\subsubsection{Flux variables}

\section{Latent heat flux}

The overall latent heat flux $r^{2}$ values for both simulations are even higher than for temperature, but decrease when considering the daytime values and become almost negligible when considering the nighttime values (Fig. 5). WRF again has the highest $r^{2}$ values for most of the groupings. When looking at the frontal passage period, the data tend to have a high $r^{2}$ during the postfrontal period (Table 7).

In most cases the WRF model has a larger bias magnitude than the MM5 model (Table 7). Overall and daytime latent heat flux is overestimated for both of the models with the largest biases occurring during the daytime. The nighttime biases for both of the models are relatively small. They are underestimated in MM5, but overestimated in WRF.

Prior to the frontal passage on 29 August, latent heat values were scattered throughout the day, which could correspond to lower moisture content (Fig. 5). Following the frontal passage (30 and 31 August), observed daytime latent heat flux increases, indicating increased moisture. Both models overestimate daytime latent heat flux for the entire study period, but WRF has larger overestimations than MM5 by approximately $20 \mathrm{Wm}^{-2}$ (Table 7). However, on 30 and 31 August both models perform similarly with overestimation biases of $\sim 21 \mathrm{Wm}^{-2}$ and $\sim 17 \mathrm{Wm}^{-2}$ for WRF and MM5, representing a difference of $6 \mathrm{Wm}^{-2}$. Both models vary in their simulation of the meteorological conditions prior to the frontal passage but resort to similar parameterizations following the front, perhaps in response to the clearer incoming solar radiation simulations.

\section{Sensible heat flux}

WRF has higher overall, and daytime, values of $r^{2}$ compared to MM5, but has lower $r^{2}$ values at night (Table 7). Both of the models had higher overall values compared to daytime clustering, while the nighttime values are low. Compared to the diurnal $r^{2}$, the $r^{2}$ is higher both for all data and for the prefrontal and postfrontal clusters (Table 7). 
Table 7. Results for $r^{2}$ and bias for all, diurnal, and frontal conditions for latent heat flux (LHFLUX), sensible heat flux (SHFLUX), ground flux (GRNDFLUX), and friction velocity (USTAR).

\begin{tabular}{lrrrrrrrr}
\hline & \multicolumn{2}{c}{ LHFLUX } & \multicolumn{2}{c}{ SHFLUX } & \multicolumn{2}{c}{ GRNDFLUX } & \multicolumn{2}{c}{ USTAR } \\
& WRF & MM5 & WRF & MM5 & WRF & MM5 & WRF & MM5 \\
\hline$r^{2}$ & 0.88 & 0.87 & 0.89 & 0.77 & 0.68 & 0.67 & 0.73 & 0.70 \\
$r^{2}$ _Day & 0.75 & 0.75 & 0.81 & 0.64 & 0.51 & 0.47 & 0.62 & 0.56 \\
$r^{2}$ _Night & 0.37 & 0.00 & 0.08 & 0.16 & 0.03 & 0.13 & 0.26 & 0.11 \\
$r^{2}$ _Prefront & 0.92 & 0.75 & 0.89 & 0.71 & 0.58 & 0.60 & 0.61 & 0.61 \\
$r^{2}$ _Postfront & 0.89 & 0.92 & 0.90 & 0.81 & 0.74 & 0.70 & 0.81 & 0.77 \\
Bias & 42.31 & 26.99 & 14.32 & 3.75 & -5.82 & -10.52 & 0.15 & 0.02 \\
Bias_Day & 73.29 & 49.84 & 32.92 & 6.83 & -46.70 & -47.40 & 0.18 & 0.01 \\
Bias_Night & 2.65 & -2.27 & -9.48 & -0.21 & 46.50 & 36.68 & 0.11 & 0.03 \\
Bias_Prefront & 60.96 & 16.46 & 21.00 & 5.39 & -14.50 & -15.72 & 0.15 & 0.00 \\
Bias_Postfront & 30.58 & 33.61 & 10.12 & 2.71 & -0.37 & -7.25 & 0.14 & 0.02 \\
RMSE & 77.77 & 70.62 & 38.89 & 31.5 & 60.85 & 56.09 & 0.17 & 0.08 \\
RMSE_Day & 103.7 & 94.04 & 50.76 & 41.52 & 69.33 & 66.35 & 0.20 & 0.08 \\
RMSE_Night & 5.18 & 7.11 & 12.29 & 7.48 & 47.86 & 39.23 & 0.14 & 0.06 \\
RMSE_Prefront & 94.26 & 74.02 & 40.94 & 35.30 & 56.22 & 49.93 & 0.19 & 0.09 \\
RMSE_Postfront & 65.32 & 68.40 & 37.55 & 28.86 & 63.59 & 59.64 & 0.16 & 0.07 \\
\hline
\end{tabular}

For the study period there was an $r^{2}$ value of 0.49 between observed sensible heat flux and water vapor mixing ratio at night. None of the models reach this level of $r^{2}$ values, but the MM5 models get closer to this relationship than the WRF model. The decrease in $r^{2}$ from sensible heat flux to latent heat flux and the decrease in the magnitude of the biases in MM5 are in agreement with the findings of Zhong et al. (2007). The WRF results agree with LeMone et al. (2009), who found that their modeled sensible heat overestimated throughout the entire study period; however, our results show lower bias for sensible heat than latent heat, which is in disagreement with the LeMone study. WRF had the higher overall, nighttime, and daytime biases than MM5. WRF and MM5 overestimated sensible heat flux for all clusters with the exception of nighttime. While the $r^{2}$ decreased for sensible heat flux compared to latent heat flux and the biases are smaller, the relative magnitude of the biases represents a larger portion of measured values. During the daytime, MM5 had an average overestimation of $7 \%$ while WRF overestimated by $33 \%$. This is a $26 \%$ disparity between the values during the daytime, but this gap decreases greatly at night, when WRF underestimated values by as much as $9 \%$ while MM5 showed almost no bias. However, WRF shows much better daytime values for $r^{2}$ and RMSE than MM5, which compensates for the poor WRF bias values to some extent.

The sensible heat flux shows a similar simulation pattern to the latent heat flux time series (Fig. 5). During the first 2 days of the study period, both models respond differently to the inconsistent sensible heat flux, but have similar responses during the 2 days following the frontal passage. Overall, Fig. 5 reflects the higher daytime biases for WRF compared with MM5 (Table 7). Sensible heating is associated with ground heating, so it is possible that temperature variations in the models, combined with differences in the moisture, could contribute to these variations. However, the 2 days following the frontal passage produce similar model responses, with WRF and MM5 overestimating sensible heat by $\sim 6 \mathrm{Wm}^{-2}$,

\section{Ground flux}

Similar to the other flux variables, the overall $r^{2}$ values were higher than either the daytime or nighttime values (Table 7). Out of all the flux variables, the overall and daytime $r^{2}$ values for ground flux are the lowest. The nighttime $r^{2}$ values are also very low. The WRF model has slightly higher $r^{2}$ values than the MM5 model overall and during the day, but is lower at night.

The ground flux biases do not follow the pattern that sensible and latent heat flux follow (Table 7). During the day both models consistently underestimate for the entire study period as well as for the 2 days following the frontal passage, and at night both models have similar overestimations. Additionally, both models have similar timing of the ground flux that lies in contrast with the observations (Fig. 5). Both models have sharp increases of ground flux in the evening that eventually diminish as the night progresses, while the observations have gradual increases in ground flux through the afternoon and then sharp drops in the morning. The ground flux is associated with increased ground temperatures as the sun reaches the ground, so the increased insolation on the 2 days following the frontal passage leads to slightly higher observed ground flux amplitudes. Both of the models capture these higher ground flux values, but have higher amplitudes of both the amount of ground flux escaping from and entering the ground, which again could be associated with the increased incoming solar radiation found in the models. 


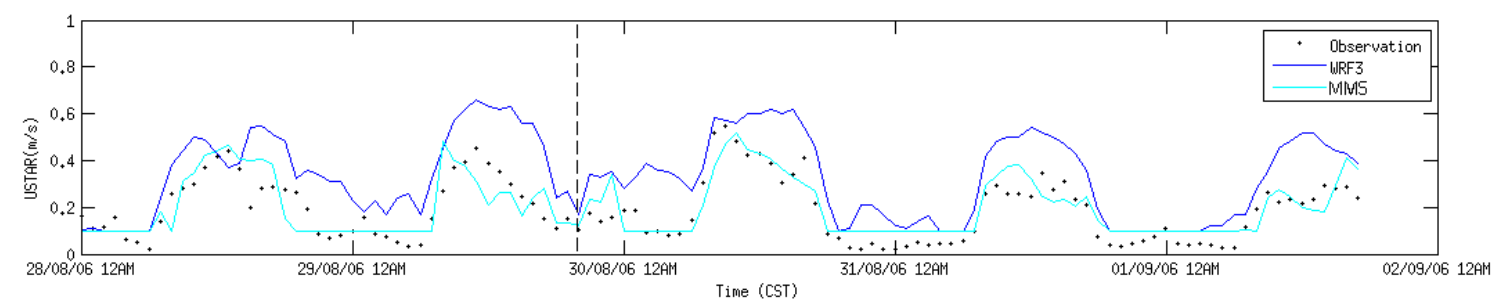

Figure 6. Time series for friction velocity.

\subsubsection{Turbulence}

Friction velocity, or $u^{*}$, is one measure of how much turbulence is being generated through shearing forces at any given time (Stull, 1988). Examining the observed and modeled and measured values can provide insight into shear turbulence that contributes to the development of the PBL. Table 7 presents the overall and diurnal $r^{2}$ and bias values for friction velocity, and Fig. 6 shows the time series for the study period.

Despite the fact that friction velocity is a small component of turbulent energy, the models are able to model it relatively well with overall $r^{2}$ values of 0.73 and 0.70 for WRF and MM5, respectively. The overall $r^{2}$ values for both of the models are higher than daytime values and much higher than the nighttime values. At night, the models are set to a minimum value of $0.1 \mathrm{~m} \mathrm{~s}^{-1}$, which does not always accurately reflect the observations that can get much smaller. Above this threshold, both models attempt to mimic nighttime $u^{*}$ behavior, but following the frontal passage, nighttime wind speeds were relatively calm (Fig. 3). On those nights observed $u^{*}$ values were well below the $0.1 \mathrm{~m} \mathrm{~s}^{-1}$ threshold, so neither model is able to simulate these values, which could have led to the low nighttime $r^{2}$ values.

Both models overestimate $u^{*}$, which could be related to the overestimations in wind speed for the models. There is no distinct cluster with the highest bias magnitudes; the largest bias for WRF occurs during the daytime but for MM5 occurs at night. WRF has the highest overall, daytime, and nighttime magnitude biases, which is in contrast with Hanna et al. (2010), who mentioned that MM5 had larger biases in the afternoon than WRF. Friction velocity is a measure of how much shear turbulence will be generated and is affected by topography and is directly related to wind speed. Compared to the other model variables, the absolute biases for friction velocity are relatively small, but assuming a maximum $u^{*}$ value of approximately $0.6 \mathrm{~m} \mathrm{~s}^{-1}$, the bias can be overestimated by nearly $30 \%$ in the WRF model.

\subsection{Planetary boundary layer}

Due to the small number of radiosonde launches available for the duration of the study period, the biases were not calculated for planetary boundary layer height. However,
PBL heights were calculated at sunrise and sunset prior to the frontal passage, and then following the frontal passage were recorded with more regularity, so the few observations available offer a better chance to look at the development and destruction of the PBL (Fig. 7). Ideally, suppressed daytime temperatures and elevated nighttime temperatures should yield similar PBL height results. However, while the daytime PBL heights are in fact underestimated during the day as expected, they are also often underestimated at night when they should be overestimated. Daytime peaks are better approximated following the frontal passage, but the PBL destruction always happens too soon.

There are various reasons for the possible variations in the onset of PBL development and destruction. Especially during the morning PBL height estimates, the late onset of solar radiation in the models could contribute to the slow development of the PBL during a time when convection leads to a rapid increase of PBL height. LeMone et al. (2009) suggest overestimations of sensible heat lead to overestimations in the convective boundary layer depth. In general, MM5 has the smallest underestimations and overestimations. However, both models replicate PBL height estimations reasonably well, with a few exceptions though: on 29 August, both models do not capture the maximum PBL height, with MM5 significantly failing, while on 1 September, MM5 performs quite well and WRF only reaches about $50 \%$ of the observed PBL height. The significant PBL underprediction in MM5 is likely due to the underprediction of sensible and latent heat in MM5 on that day (Fig. 5), which in turn might be associated with the deficient simulation of shortwave radiation by MM5 on the same day.

Rappenglück et al. (2008) speculated whether PBL development was slower on ozone exceedance days due to cooler temperatures delaying PBL development. In the postfrontal environment temperatures were in fact cooler (Fig. 3), but none of the models were able to simulate temperature minimums for the nights of 30 or 31 August. WRF gets closest to the observed temperatures while MM5 has a larger bias following the front, which may explain why MM5 overestimated noontime PBL height on 30 August. WRF, however, besides getting closer to early morning temperatures, underestimated daytime temperatures, which may explain the underestimation of the PBL heights by WRF on 31 August1 September (Fig. 7). Increased PBL height allows for lower 


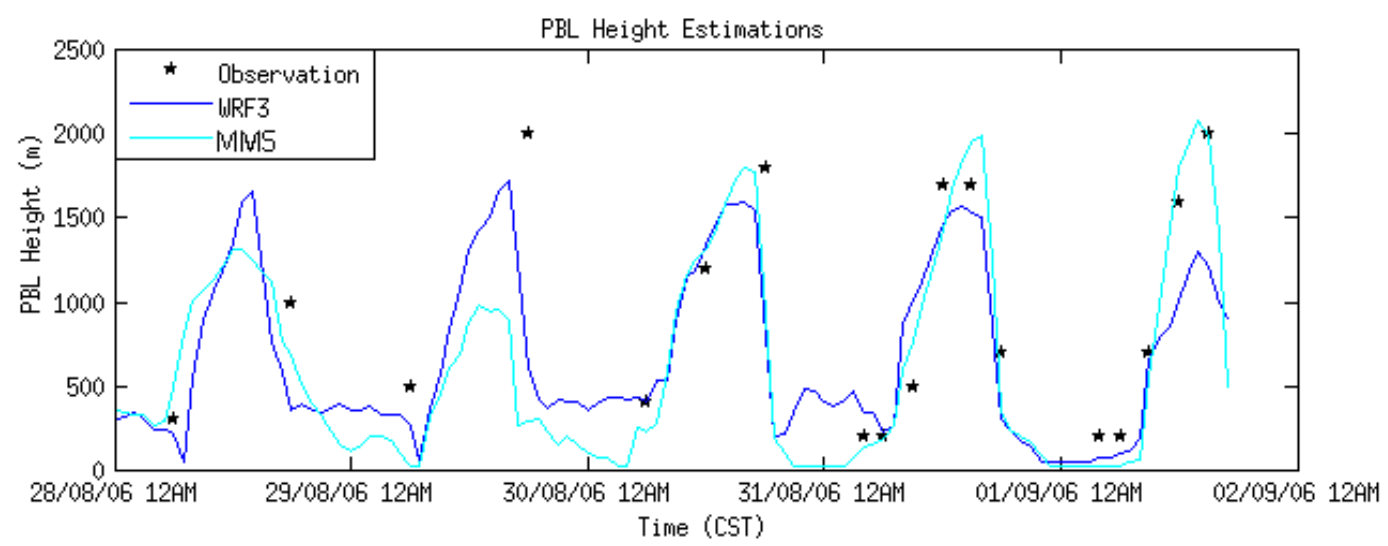

Figure 7. Comparison of observed and simulated PBL height for the study period. The WRF simulation tended to underestimate more than either of the MM5 simulations.

ozone concentrations, so it is no surprise that using MM5 simulations as a meteorological driver for air quality modeling led to underestimation of ozone on 31 August and 1 September by 25-30 ppb (Banta et al., 2011; Ngan et al, 2012).

\section{Conclusions}

Although WRF v3.5.1 does not perform as well as MM5 v3.6.1 in predicting PBL heights, it does a better job in capturing energy budget and most of the general variables (with exception of wind speed/direction and water vapor mixing ratio). Energy balance partitioning can have an effect on standard and planetary boundary layer height variables. Both models overestimate incoming solar radiation, which implies a surplus of energy that could be exhibited in either the partitioning of the surface energy variables or in some other aspect of the meteorological modeling not examined here. This scenario would also imply that there is more energy available for the nighttime system, which should mean increased temperatures and higher boundary layer height estimations. While nighttime temperatures seem to reflect this increased energy for both models, PBL height estimations only reflect it in WRF.

The nighttime temperature bias disparity in the models following the frontal passage could reflect the disparity in moisture. The MM5 model consistently had much drier conditions than the WRF model, which could mean more energy available to other parts of the meteorological system. On the clearest day of the study period MM5 had increased latent heat flux, which could lead to higher evaporation rates and lower moisture in the model. However, this latent heat disparity between the two models is not visible during any other part of the study, so examining sequential cloud-free days would be necessary to see whether the moisture and latent heat effect was sustained. The full effects of moisture on the energy balance cannot be determined here other than as a po- tential reason for inconsistent model outputs. The differences in the land data sets used to initialize and update each model make this situation plausible.

The frontal passage allowed this study to examine these variables both under prefrontal and postfrontal conditions, and it was found that a frontal passage affects the performance of most of the variables, including the radiation, flux, and turbulence variables, at times creating significant differences in the $r^{2}$ values. Ultimately the clear, sunny days offered the most insight into the potential effects of the energy balance variables on standard variables and planetary boundary layer height. These 2 days were also 2 of the highest $8 \mathrm{~h}$ ozone peak days on record for the year. Since these kinds of days are favorable for high ozone production, the energy balance variables reproduced on these days could more accurately represent meteorological conditions. Accurately determining the energy balance variables could in turn produce better standard meteorology and PBL heights, which are essential in determining accurate ozone concentrations.

The results presented in this paper are restricted to the validation of one $4 \mathrm{~km}$ domain grid cell with observations in this specific grid cell. We do not claim that these validations are valid throughout the domain and for each grid cell as this would require a corresponding network of micrometeorological observations. However, we believe that a point-to-grid validation on one $4 \mathrm{~km}$ domain grid cell may still be helpful in elucidating different behaviors and/or progresses in different models to simulate boundary layer properties.

Acknowledgements. We are grateful for financial and infrastructural support provided by the UH-CC, and we would like to thank Dr. Fong Ngan (NOAA-ARL) for valuable discussions.

Edited by: P. Jöckel 


\section{References}

Air Resources Laboratory: Eta Data Assimilation System (EDAS) Archive Information, available at: http://ready.arl.noaa.gov/ edas80.php (last access: 2 December 2013), 2013.

Banta, R. M., Senff, C., Nielsen-Gammon, J., Darby, L., Ryerson, T., Alvarez, R., Spandberg, S., Williams, E., and Trainer, M.: A bad air day in Houston, B. Am. Meteorol. Soc., 86, 657-669, 2005.

Banta, R. M., Senff, C., Alvarez, R., Langford, A., Parrish, D., Trainer, M., Darby, L., Hardesty, R., Lambeth, B., Neuman, J., Angevine, W., Nielsen-Gammon, J., Sandberg, S., and White, A.: Dependence of daily peak $\mathrm{O}_{3}$ concentrations near Houston, Texas on environmental factors: wind speed, temperature, and boundary-layer depth, Atmos. Environ., 45, 162-173, 2011.

Borge, R., Alexandrov, V., del Vas, J. J., Lumbreras, J., and Rodriguez, E.: A comprehensive sensitivity analysis of the WRF model for air quality applications over the Iberian Peninsula, Atmos. Environ., 42, 8560-8574, 2008.

Byun, D. W. and Schere, K.: Review of the governing equations, computational algorithms, and other componenets of the Models3 community multiscale air quality (CMAQ) modeling system, Appl. Mech. Rev., 59, 51-77, 2006.

Chen, F. and Dudhia, J.: Coupling an advanced land surface hydrology model with the Penn State-NCAR MM5 modeling system. Part 1: Model implementation and sensitivity, Mon. Weather Rev., 129, 569-585, 2001.

Clements, C. B., Zhong, S., Goodrick, S., Li, J., Potter, B. E., Bian, X., Heilman, W. E., Charney, J. J., Perna, R., Jang, M., Lee, D., Patel, M., Street, S., and Aumann, G.: Observing the dynamics of wildland grass fires - FireFlux - a field validation experiment, B. Am. Meteorol. Soc., 88, 1369-1382, 2007.

Cuchiara, G. C., Li, X., Carvalho, J., and Rappenglück, B.: Intercomparison of planetary boundary layer parameterization and its impacts on surface ozone formation in the WRF/Chem model for a case study in Houston/Texas, Atmos. Environ., 96, 175-185, doi:10.1016/j.atmosenv.2014.07.013, 2014.

Czader, B. H., Li, X., and Rappenglück, B.: CMAQ modeling and analysis of radicals, radical precursors and chemical transformations, J. Geophys. Res., 118, 11376-11387, doi:10.1002/jgrd.50807, 2013.

Day, B. M., Rappenglück, R., Clements, C., Tucker, S., and Brewer, W.: Nocturnal boundary layer characteristics and land breeze development in Houston, Texas during TexAQS II, Atmos. Environ., 44, 4014-4023, 2010.

Dudhia, J.: Numerical study of convection observed during the winter monsoon experiment using a mesoscale two-dimensional model, J. Atmos. Sci., 46, 3077-3107, 1989.

Gilliam, R. and Pleim, J.: Performance assessment of new land surface and planetary boundar layer physics in the WRF-ARW, J. Appl. Meteorol. Clim., 49, 760-774, 2010.

Grell, G. A. and Devenyi, D.: A generalized approach to parameterizing convection combining ensemble and data assimilation techniques, Geophys. Res. Lett., 29, 38.1-38.4, doi:10.1029/2002GL015311, 2002.

Grell, G. A., Dudhia, J., and Stauffer, D.: A description of the fifthgeneration Penn State/NCAR Mesoscale Model (MM5), NCAR Tech. Note NCAR/TN-3981STR, 122 pp., 1994.

Hanna, S. R., Reen, B., Hendrick, E., Santos, L., Stauffer, D., Deng, A., McQueen, J., Tsudulko, M., Janjic, Z., Jovic, D., and Sykes,
R.: Comparison of observed, MM5, and WRF-NMM modelsimulated, and HPAC-assumed boundary layer meteorological variables for 3 days during the IHOP field experiment, Bound.Lay. Meteorol., 134, 285-306, 2010.

Hong, S. Y. and Pan, H. L.: Nonlocal boundary layer vertical diffusion in a medium range-forecast model, Mon. Weather Rev., 124, 2322-2339, 1996.

Hong, S. Y., Dudhia, J., and Chen, S. H.: A revised approach to ice microphysical processes for the bulk parameterization of clouds and precipitation, Mon. Weather Rev., 132, 103-120, 2004.

Hu, X. M., Nielsen-Gammon, J., and Zhang, F.: Evaluation of three planetary boundary layer schemes in the WRF model, J. Appl. Meteorol. Clim., 49, 1831-1844, 2010.

Kain, J. S.: The Kain-Fritsch convective parameterization: An update, J. Appl. Meteorol., 43, 170-181, 2004.

Kljun, N., Calanca, P., Rotach, M. W., and Schmid, H. P.: A simple parameterisation for flux footprint predictions, Boundary Layer Meteorol., 112, 503-523, doi:10.1023/B:BOUN.0000030653.71031.96, 2004

Langford, A. O., Tucker, S., Senff, C., Banta, R., Brewer, W., Alvarez, R., Hardesty, R., Lerner, B., and Williams, E.: Convective venting and surface ozone in Houston during TexAQS2006, J. Geophys. Res., 115, D16305, doi:10.1029/2009JD013301, 2010.

LeMone, M., Chen, F., Tewari, M., Dudhia, J., Geerts, B., Miao, Q., Coulter, R., and Grossman, R.: Simulating the IHOP_2002 fairweather CBL with the WRF-ARW-Noah modeling system. Part 1: Surface fluxes and CBL Structure and evolution along the eastern track, Mon. Weather Rev., 138, 722-744, 2009.

Mao, Q., Gautney, L. L., Cook, T. M., Jacobs, M. E., Smith, S. N., and Kelsoe, J. J.: Numerical experiments MM5-CMAQ sensitivity to various PBL schemes, Atmos. Environ., 40, 3092-3110, 2006.

Mlawer, E. J., Taubman, S., Brown, P., Iacono, M., and Clough, S.: Radiative transfer for inhomogeneous atmosphere: RRTM, a validated correlated- $k$ model for the longwave, J. Geophys. Res., 102, 16663-16682, 1997.

National Weather Service Environmental Modeling Center: NAM: the North American Mesoscale Forecast System, available at: http://www.emc.ncep.noaa.gov/index.php?branch=NAM (last access: 24 November 2013), 2013.

Ngan, F. and Byun, D.: Classification of weather patterns and associated trajectories of high-ozone episodes in the HoustonGalveston-Brazoria area during the 2005/06 TexAQS-II, J. Appl. Meteorol. Clim., 50, 485-499, 2011.

Ngan, F., Byun, D., Kim, H. C., Lee, D. G., Rappenglück, B., and Pour-Biazar, A.: Performance assessment of retrospective meteorological inputs for use in air quality modeling during TexAQS 2006, Atmos. Environ., 54, 86-96, 2012.

Rappenglück, B., Perna, R., Zhong, S., and Morris, G.: An analysis of the vertical structure of the atmosphere and the upper-level meteorology and their impact on surface ozone levels in Houston, Texas, J. Geophys. Res., 113, D17315, doi:10.1029/2007JD009745, 2008.

Skamarock, W. C., Klemp, J., Dudhia, J., Gill, D., Barker, D., Duda, M., Hwang, X. Y., and Powers, J.: A Description of the Advanced Research WRF Version 3, NCAR Tech Note NCAR/TN-4751STR, UCAR Communications, Boulder, CO, 125 pp., 2008. 
Steenveld, G. J., Wokke, M., Zwaaftink, C., Pijlman, S., Heusinkveld, B., Jacobs, A., and Holtslag, A.: Observations of the radiation divergence in the surface and its implication for its parameterization in numerical weather prediction models, J. Geophys. Res., 115, D06107, doi:10.1029/2009JD013074, 2010.

Stull, R. B.: An Introduction to Boundary Layer Meteorology, 13th edn., Atmospheric and Oceanographic Sciences Library, Springer Publishers, 1988.

Tucker, S. C., Banta, R., Langford, A., Senff, C., Brewer, W., Williams, E., Lerner, B., Osthoff, H., and Hardesty, R.: Relationships of coastal nocturnal boundary layer winds and turbulence to Houston ozone concentrations during TexAQS 2006, J. Geophys. Res., 115, D10304, doi:10.1029/2009JD013169, 2010.
Wilczak, J. M., Djalalova, I., McKeen, S., Bianco, L., Bao, J. W., Grell, G., Peckham, S., Mathur, R., McQueen, J., and Lee, P.: Analysis of regional meteorology and surface ozone during the TexAQS II field program and an evaluation of the NMM-CMAQ and WRF-Chem air quality models, J. Geophys. Res., 114, D00F14, doi:10.1029/2008JD011675, 2009.

Zhong, S., In, H. J., and Clements, C.: Impact of turbulence, land surface, and radiation parameterizations on simulated boundary layer properties in a coastal environment, J. Geophys. Res., 112, D13110, doi:10.1029/2006JD008274, 2007. 